
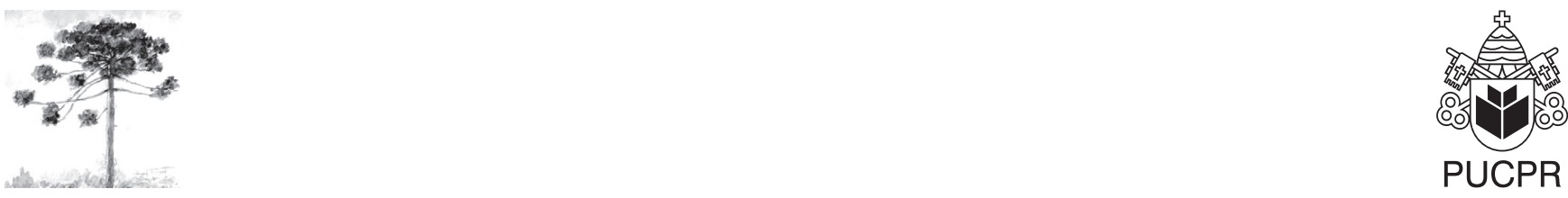

PUCPR

\title{
Interaçóes estacionais entre beija-flores (Trochilidae) em uma regiáo de ecótone no município de Piraquara, Paraná
}

\author{
Seasonal interactions between hummingbirds (Trochilidae) in a region \\ of ecotone in Piraquara city, Paraná
}

Jaqueline Evelyn Persegona ${ }^{[a]}$, Leandro Corrêa ${ }^{[\mathrm{b}]}$, James Joseph $\operatorname{Roper}^{[\mathrm{c}]}$

[a] Graduanda em Ciências Biológicas pela Pontifícia Universidade Católica do Paraná (PUCPR), Curitiba, PR - Brasil, e-mail: evelynebio@gmail.com

[b] Programa de Pós-Graduação em Ecologia e Conservação, Universidade Federal do Paraná (UFPR), Curitiba, PR - Brasil, e-mail: letrogon@gmail.com

[c] Programa de Pós-Graduação em Ecologia e Conservação Universidade Federal do Paraná (UFPR), Curitiba, PR - Brasil, e-mail: jjroper@gmail.com

\section{Resumo}

Este trabalho teve por objetivo acompanhar e analisar as interações inter e intra-específicas de beija-flores e como estas interações mudaram ao longo do ano. O estudo foi realizado em um remanescente de floresta no município de Piraquara, Paraná. Beija-flores foram filmados mensalmente entre março de 2008 e abril de 2009. Foi possível identificar indivíduos focais, medir intervalos de tempo durante o qual o indivíduo focal ficou no bebedouro e anotar o momento e a espécie envolvida em uma interação. A espécie mais comum foi Leucocbloris albicollis que foi observado em 2.300 visitas, seguido por Colibri serrirostris, Amazilia versicolor, Florisuga fusca e Thalurania glaucopis. Há variações entre as espécies no tempo de exploração do recurso: $L$. albicollis tende a ficar $21 \mathrm{~s} \mathrm{em} \mathrm{cada} \mathrm{visita,} \mathrm{em} \mathrm{contraste} \mathrm{com} \mathrm{F.} \mathrm{fusca} \mathrm{que} \mathrm{tende}$ a ficar somente $7 \mathrm{~s}$. As conseqüências destas interações complexas podem estruturar a comunidade com uma hierarquia flutuante, que varia ao longo do ano.

Palavras-chave: Comportamento. Territorialidade. Hierarquia de dominância. 


\begin{abstract}
This work had for objective to follow and to analyze the intra-specific Inter interactions and of hummingbirds and as these interactions had moved throughout the year. The study it was carried through in a farm in the city of Piraquara, Paraná. Hummingbirds had been filmed monthly between march of 2008 and april of 2009. It was possible to identify focal individuals, to measure time intervals during which the focal individual was in the water through and to write down the moment and the involved species in an interaction. The species most common was Leucochloris albicollis that were observed in 2.300 visits, followed by Colibri serrirostris, Amazilia versicolor, Florisuga fusca and Thalurania glaucopis. It has variations between the species in the time of exploration of the resource: $\mathrm{L}$. albicollis tends to be 21 s in each visit, in contrast with $\mathrm{F}$. fusca that it tends to be only $7 \mathrm{~s}$. The consequences of these complex interactions can structuralize the community with a floating hierarchy, that varies throughout the year.
\end{abstract}

Keywords: Behavior. Territoriality. Dominance hierarchy.

\section{Introduçáo}

Animais que compartilham os mesmos recursos frequentemente sofrem com a competição. Entender as interações que resultam desta competição é importante para entender a estrutura das comunidades. Quando recursos são limitados, espera-se que haja interações mais fortes; por outro lado, quando são abundantes, as interações podem ser menos importantes (1).

Os beija-flores (Trochilidae) são aves exclusivamente neotropicais, e utilizam em sua alimentação principalmente o néctar, sendo geralmente influenciados pela mudança na disponibilidade de seus recursos alimentares nas diferentes estações do ano (2). Várias espécies de aves nectarívoras apresentam como estratégia de forrageio o estabelecimento de territórios de alimentação, ou seja, a defesa de fontes de néctar espacialmente concentradas (3-7). A defesa da fonte de néctar consiste em alternar períodos de alimentação com períodos de pouso em locais próximos à fonte utilizada, vigiando-a e agredindo indivíduos invasores (8).

Graças ao alto gasto energético na procura de alimento, e ao número potencialmente limitado de flores, possivelmente existe muita competição inter e intraespecífica por este recurso. Além disso, em virtude da maior importância da obtenção deste recurso para espécies menores (8), pode ser que exista uma relação não necessariamente linear em termos de uma hierarquia de dominância nesta competição. $\mathrm{O}$ balanço entre a energia adquirida pelo uso exclusivo de uma área de alimentação e a energia gasta defendendo esta determina se a defesa é energeticamente vantajosa ou não (9). Para beija-flores, os custos da territorialidade são representados pelo tempo e energia associados à defesa (10-12), aos possíveis riscos de predação $(13,14)$ e ao dano causado por interações com intrusos (15).

A teoria de forrageio ótimo sugere que as interações devem ser mais fortes durante épocas de escassez e, entre as espécies ou indivíduos com menos flores disponíveis para o forrageamento, a competição deve ser ainda mais importante (16).

O comportamento de defesa é uma maneira de minimizar a competição a partir de interações agressivas que determinam relações de dominância entre os indivíduos envolvidos (17-21). Os beija-flores oferecem um bom modelo para estudar interações e ciclos anuais. No Sul do Brasil, em especial na região de Curitiba, estas aves apresentam ciclos de abundância (migração), que variam dependendo das espécies e da época do ano (James J. Roper obs. pess., 2009).

O objetivo deste estudo foi acompanhar e analisar as interações inter e intraespecíficas em beija-flores e o padrão de ocorrência das espécies ao longo do ano. Especificamente, foram identificadas a hierarquia de dominância e a taxa de visitas a um recurso alimentar artificial de espécies durante mais de um ano de observações.

\section{Material e métodos}

O estudo foi realizado entre março de 2008 e abril de 2009, em uma chácara próxima a fragmentos florestais antropicamente perturbados no município de Piraquara, Estado do Paraná (2531'17"S, $\left.49^{\circ} 05^{\prime} 33^{\prime \prime W}\right)$. A vegetação é caracterizada pelo ecótone 
das Florestas Ombrófilas mista e densa. A Floresta Ombrófila Mista ou Floresta com Araucária ocorre principalmente nos três Estados sulinos, entre os quais o Paraná é o que apresenta a maior extensão desta unidade fitoecológica $(22,23)$. A Floresta Ombrófila Densa é influenciada diretamente pelas massas de ar quente e úmido do Oceano Atlântico, apresentando chuvas relativamente intensas e bem distribuídas ao longo do ano (24).

O clima da região, de acordo com a classificação climática de Köppen, é CfB (subtropical úmido), mesotérmico com verões frescos, geadas frequentes e sem estação seca definida. Apresenta temperatura média no mês mais frio inferior a $18^{\circ} \mathrm{C}$, e no mais quente, inferior a $22^{\circ} \mathrm{C}$. A precipitação média anual é de $1.384 \mathrm{~mm}$, sendo outubro, novembro e dezembro os meses mais chuvosos e junho, julho e agosto os meses mais secos (25).

A área de estudo possui bebedouros abastecidos e disponíveis durante o ano todo, atraindo muitos beija-flores; dentre estes um foi selecionado para a realização das filmagens. As observações foram realizadas de uma a três vezes por mês durante o período de estudo. Os beija-flores foram filmados no bebedouro com uma câmera digital Sony ${ }^{\circledR}$, sendo a duração das gravações de aproximadamente $90 \mathrm{~min}$, em cada réplica, realizadas sempre no período entre $7 \mathrm{~h}$ e $15 \mathrm{~h}$. A filmadora era estrategicamente colocada e iniciava a filmagem de um bebedouro até acabar a fita (90 min). Posteriormente, a fita era observada para anotar os indivíduos (focais) usando o recurso alimentar artificial e outros indivíduos (intrusos) que vieram para tentar usá-lo no momento em que estava ocupado. No momento em que um beija-flor chegava ao bebedouro, a espécie era identificada com auxílio de guias de campo $(26,27)$. Foi utilizado um caderno de campo com colunas indicando a data da observação, a espécie em código (Tabela 2), sexo e idade quando possível, indivíduo, hora de chegada e saída do recurso, comportamento, número de vezes que se alimentou e uma coluna para indivíduo intruso. Nesse caso, a espécie intrusa (ave que chegava depois do outro que já se encontrava no bebedouro) foi identificada e o tipo de interação foi anotado. $\mathrm{O}$ indivíduo focal foi acompanhado durante sua estadia no bebedouro, e cada indivíduo recebeu um número código para estimar quantas vezes visitava o recurso durante a amostragem. Se o beija-flor desaparecia do campo de visão, qualquer outro indivíduo da mesma espécie que chegava era considerado como sendo outro indivíduo. Sabe-se que os mesmos indivíduos visitaram os bebedouros mais de uma vez, entretanto, esta variável não foi considerada, pelo fato de que não foi possível reconhecer cada ave individualmente e assim afirmar se era a mesma visitando o recurso após sair do campo de visão. O comportamento e as interações dos beija-flores foram anotados em códigos, conforme a Tabela 1:

Tabela 1 - Códigos usados para identificação do comportamento e das interações entre indivíduos

\begin{tabular}{|c|c|c|}
\hline Código & Significado & Quando foi aplicado \\
\hline $\mathrm{P}$ & Pousou & $\begin{array}{l}\text { Quando o indivíduo focal chegou e pousou no bebedouro, pois muitos chegaram e não } \\
\text { pousaram. Nesse último caso, não foi utilizado nenhum código }\end{array}$ \\
\hline PS & Perseguiu & Quando o indivíduo focal foi quem perseguiu outro indivíduo, nesse caso o intruso \\
\hline AT & Atacou & $\begin{array}{l}\text { Quando o indivíduo focal atacou outro indivíduo (intruso) que estava pousado no bebedouro ou } \\
\text { quando chegou depois }\end{array}$ \\
\hline FA & Foi atacado & Quando o intruso atacou o indivíduo focal \\
\hline FE & Foi embora & $\begin{array}{l}\text { Quando o indivíduo focal desapareceu do campo de visão, ou seja, quando foi embora sem } \\
\text { interferência de outro indivíduo }\end{array}$ \\
\hline $\mathrm{E}$ & Escapou & $\begin{array}{l}\text { Quando o indivíduo focal foi embora no momento em que outro chegou ao bebedouro, ou } \\
\text { quando se sentiu ameaçado por indivíduos presentes no mesmo recurso }\end{array}$ \\
\hline $\mathrm{V}$ & Voou & $\begin{array}{l}\text { Quando o indivíduo focal voou e não saiu do campo de visão, na maioria das vezes retornou ao } \\
\text { bebedouro }\end{array}$ \\
\hline
\end{tabular}

Fonte: Dados da pesquisa. 
Foram consideradas interações os códigos PS, AT e FA, nos quais ocorreram interações entre indivíduos da mesma espécie, como também entre espécies diferentes. Já os códigos P, FE, E e V são referentes ao comportamento dos beija-flores ao se alimentarno recurso artificial. Não foi utilizado código quando oindivíduo focal pairou no bebedouro; assim a coluna referente ao comportamento ficou em branco. Também não foi utilizado para o número de vezes que esse se alimentou; neste último caso, a coluna foi preenchida com o número referente à alimentação.

Para testar a hipótese de que existia uma hierarquia de dominância entre as espécies de beija-flores, todas as interações foram contabilizadas. Quando há uma dominância, espera-se que exista assimetria entre interações. Por exemplo, uma espécie tende a atacar mais vezes a outra do que o contrário (8).

Para verificar o ciclo anual, o número de espécies e a taxa de visitas foram estimados para cada espécie mensalmente. Esta taxa foi calculada a partir da hora de início e término da filmagem por meio do número de visitas e indivíduos de cada espécie neste intervalo A partir desses valores, foi possível calcular a proporção de cada espécie que visitava os bebedouros nas filmagens. Também, da mesma maneira, foi calculada a proporção de intrusos por espécie durante os mesmos intervalos. Foram comparadas as ocorrências das espécies nas filmagens com capturas realizadas ao longo do ano na mesma área, por meio de uma pesquisa paralela que realizou a marcação e recaptura destas aves (dados não publicados pelos autores).

O valor esperado de interações, caso não houvesse hierarquia, seria exatamente a probabilidade de visita de uma espécie multiplicada pela probabilidade de visita da mesma ou de outra espécie. Esta probabilidade é multiplicada pelo número de visitas totais durante o intervalo de observação para ter o número esperado de interações. Da mesma forma, os valores observados foram calculados com base nas visitas dos intrusos. Assumindo que o indivíduo já presente no bebedouro (o focal) está fixo e quem chega está escolhendo interagir, podemos calcular as probabilidades de interagir. Então, a proporção de visitas da espécie focal multiplicada pela proporção de visitas do intruso, por mês, deve resultar na probabilidade dessas espécies se encontrarem por casualidade. Se o valor observado é maior do que o valor calculado, isto indica que o intruso tende a se aproximar mais do que o esperado, e se o valor é menor do que o calculado, o intruso tende a evitar a espécie focal.
Também foram anotadas interações agonísticas, como ataque (quando o focal foi na direção do intruso), foi atacado (quando o intruso foi na direção do focal), perseguição (quando o indivíduo focal persegue outro indivíduo) e fuga (quando o indivíduo focal vai embora quando outro chega ou mesmo foge quando ocorre uma interação entre indivíduos próximos).

Como consequência das interações, a taxa de alimentação pode ser comprometida. Estimamos a taxa de alimentação, a frequência de interações e o número de indivíduos visitando o bebedouro durante cada amostra. Espera-se uma relação negativa, ou seja, quanto maior for a interferência, como consequência, menor será a taxa de alimentação, que foi testada por análise de correlação.

\section{Resultados}

Um total de dez espécies foi observado visitando os bebedouros durante o estudo: Leucochloris albicollis, Amaziliaversicolor, Thaluraniaglaucopis, Florisuga fusca, Colibri serrirostris, Anthracothorax nigricollis, Chlorostilbon lucidus, Calliphlox amethystina, Eupetomena macroura e Clytolaema rubricauda (Figura 1), com um total de 2.436 indivíduos observados nos bebedouros e um total de 646 interações. O número de interações por mês foi muito variável e oscilou entre 1 e 213. Também o número de visitantes nos bebedouros variou por amostra, entre 16 e 613 e o número de espécies visitantes por mês variou entre 2 e 8 (Tabela 2). Duas espécies foram capturadas na mesma área, mas não foram observadas em interações: Amazilia fimbriata (Amfi), Stephanoxis lalandi (Stla) (Figura 1B) (Dados não publicados pelos autores).

As interações variavam no decorrer do tempo (Figura 2). Nem todas as espécies foram observadas interagindo interespecificamente, o que se pode constatar comparando as Figuras 2B e 2C. Visto que nem todas as espécies foram encontradas todo o tempo, as análises se limitaram ao tempo em que estiveram presentes. Entretanto, o valor de interações esperadas pode ser calculado a partir da proporção de encontros de cada espécie multiplicado pela mesma proporção de qualquer outra espécie. Quando este valor é comparado ao observado, percebemos que as interações parecem ocorrer aleatoriamente, ou que são proporcionais à taxa de visita conjunta das espécies (Figura 3). Isto sugere que as interações são aleatórias (inclinação da reta $=1$ indica aleatoriedade). 
Tabela 2 - Códigos e época de ocorrência das espécies de beija-flores na área de estudo

\begin{tabular}{|c|c|c|c|c|c|c|c|c|c|c|c|c|c|c|c|}
\hline Espécies & Código & $\mathbf{M}$ & A & $\mathbf{M}$ & J & J & $\mathbf{A}$ & $\mathrm{S}$ & $\mathbf{O}$ & $\mathbf{N}$ & $\mathbf{D}$ & J & $\mathbf{F}$ & $\mathbf{M}$ & $\mathbf{A}$ \\
\hline Leucocbloris albicollis & Leal & $\mathrm{X}$ & $\mathrm{X}$ & $\mathrm{X}$ & $\mathrm{X}$ & $\mathrm{X}$ & $\mathrm{X}$ & $\mathrm{X}$ & $\mathrm{X}$ & $\mathrm{X}$ & $\mathrm{X}$ & $\mathrm{X}$ & $\mathrm{X}$ & $\mathrm{X}$ & $\mathrm{X}$ \\
\hline Amazilia versicolor & Amve & & & & & & $\mathrm{X}$ & $\mathrm{X}$ & $\mathrm{X}$ & $\mathrm{X}$ & & $\mathrm{X}$ & $\mathrm{X}$ & $\mathrm{X}$ & \\
\hline Thalurania glaucopis & Thgl & $\mathrm{X}$ & $\mathrm{X}$ & $\mathrm{X}$ & $\mathrm{X}$ & $\mathrm{X}$ & $\mathrm{x}$ & $\mathrm{x}$ & $\mathrm{x}$ & $\mathrm{x}$ & $\mathrm{X}$ & $\mathrm{x}$ & $\mathrm{x}$ & $\mathrm{x}$ & \\
\hline Colibri serrirostris & Cose & $\mathrm{X}$ & $\mathrm{X}$ & & & & & & $\mathrm{X}$ & $\mathrm{X}$ & & $\mathrm{X}$ & $\mathrm{X}$ & & \\
\hline Florisuga fusca & Flfu & $\mathrm{X}$ & $\mathrm{X}$ & & & $\mathrm{X}$ & & & $\mathrm{X}$ & $\mathrm{X}$ & $\mathrm{X}$ & $\mathrm{X}$ & $\mathrm{X}$ & $\mathrm{X}$ & $\mathrm{X}$ \\
\hline Anthracothorax nigricollis & Anni & $\mathrm{X}$ & $\mathrm{X}$ & & & & & & $\mathrm{X}$ & $\mathrm{X}$ & $\mathrm{X}$ & $\mathrm{x}$ & & & \\
\hline Chlorostilbon lucidus & Chlu & $\mathrm{X}$ & $\mathrm{X}$ & & & & & & $\mathrm{X}$ & $\mathrm{X}$ & $\mathrm{X}$ & $\mathrm{X}$ & $\mathrm{x}$ & & \\
\hline Eupetomena macroura & Euma & & & & & & & & & & & & $\mathrm{X}$ & & \\
\hline Calliphlox amethystina & Caam & & & & & & $\mathrm{X}$ & & & & & $\mathrm{X}$ & & & \\
\hline Clytolaema rubricauda & Clru & & & & & $\mathrm{X}$ & & & & & & & & & \\
\hline
\end{tabular}

Fonte: Dados da pesquisa.

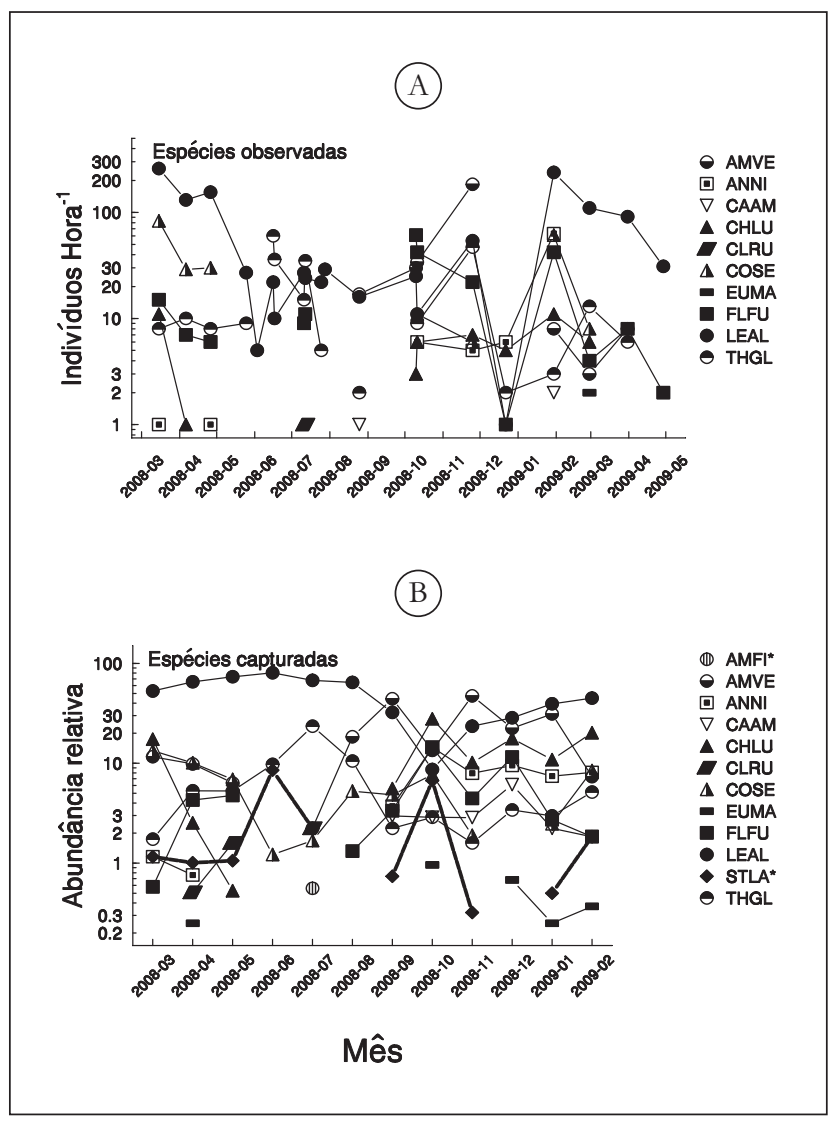

Figura 1 - A - Espécies observadas em cada mês e número de visitas por hora na área de estudo. B - Abundância relativa das espécies capturadas no mesmo local (Dados não publicados dos autores)

Fonte: Dados da pesquisa.
Quando examinamos os tipos de comportamento, no entanto, descobrimos que há diferenças entre cada espécie (Figura 4). Por exemplo, A. versicolor quase não paira durante sua estadia no bebedouro, em contraposição a $A$. nigricollis, que quase sempre está pairando. Quanto a possíveis hierarquias entre as espécies, cuja definição seria dada pela proporção da diferença entre atacar e ser atacado, só foi observada clara diferença entre algumas delas. Por exemplo, quando C. serrirostris está na situação de espécie focal, tende a atacar muito mais $L$. albicollis (49 vezes em 51 oportunidades) do que L. albicollis, quando focal, tende a atacar C. serrirostris (1 em 30 oportunidades). Semelhantemente, T. glaucopis tende a atacar a $A$. versicolor. Excetuando-se estas espécies, as outras não apresentaram tendências hierárquicas fortes (Figura 5).

Interessantemente, esta hierarquia parece não interferir na taxa de alimentação e nos intervalos desta ação no bebedouro. Estas variáveis não mostram diferenças entre espécies ( $p>0,05)$, ou seja, apesar das interações, aparentemente não há muito impacto em termos de interferência no acúmulo de recursos.

Sem consideraras espécies individualmente, e somente analisando a interferência geral e o número de indivíduos, ou o número de espécies em cada amostra, descobrimos que há interferência. Esta interferência está aparentemente associada com o número de indivíduos e com o número de espécies em cada amostra. Quando ocorrem mais indivíduos 
ou espécies, há maior taxa de consumo (Figura 6). Mediante a análise de regressão múltipla, evidencia-se que estas duas variáveis na análise demonstram que, uma vez que o número de espécies esteja no modelo, o número de indivíduos não é importante ( $p>0,10)$. Ou seja, o que interfere mais é o número de espécies e, ao retirarmos seu efeito, não há mais influência do número de indivíduos. Assim, a relação com o número de espécies explica $55 \%$ da taxa de consumo $(p<0,05$, Figura $6 B)$.

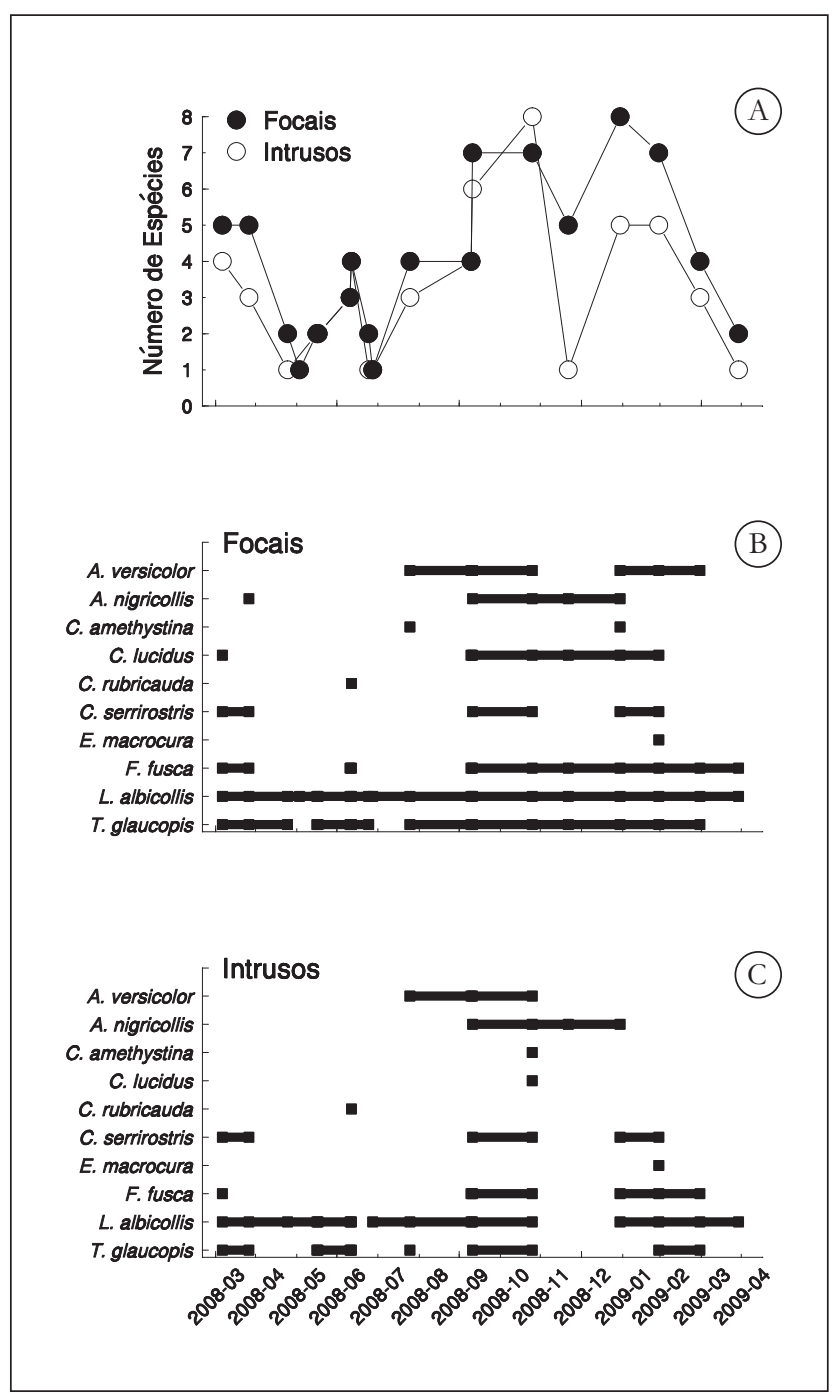

Figura 2 - Ocorrência de interações e variação das espécies durante o ano. A - Comparação entre o número de espécies focais e intrusas em relação aos meses do ano; B - Meses em que cada espécie foi observada como focal; $\mathrm{C}$ - Meses em que cada espécie foi observada como intrusa

Fonte: Dados da pesquisa.

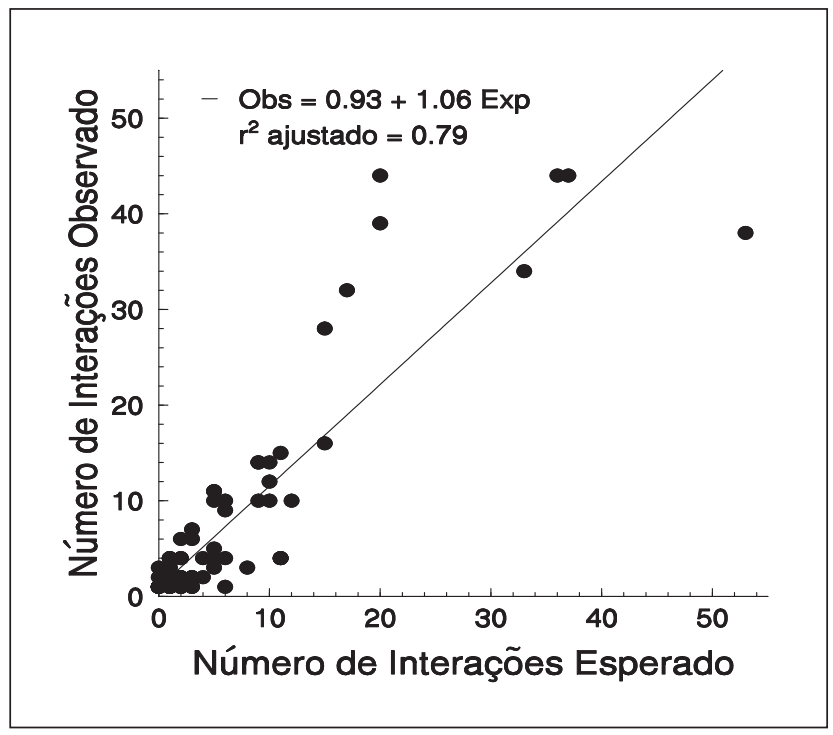

Figura 3 - Relação entre o número de interações ocorridas e esperadas

Fonte: Dados da pesquisa.

\section{Discussão}

A variação no número de espécies (2 a 10) e o número de indivíduos por amostra (16 a 613) sugerem um complexo ciclo anual de migração que varia entre as espécies (Figuras 1 e 2). Constatou-se também que, durante o inverno, tanto o número de espécies quanto de indivíduos é menor (Tabela 2). A sazonalidade é um fenômeno conhecido em espécies que reproduzem no hemisfério Norte $(28,29)$, mas ainda é pouco estudada no hemisfério Sul (30).

As interações entre as espécies não geraram hierarquias claras, talvez em virtude da complexidade do ciclo anual, visto que nem todas as espécies encontram sempre indivíduos de outras nos bebedouros (Figuras 2 e 5). Também, uma vez que o recurso nos bebedouros não é limitado, as interações podem ser mais pacíficas do que seriam na natureza. Esta ideia é suportada pela relação positiva entre taxa de consumo e número e número de espécies (Figura 6).

Isto sugere que, para as espécies observadas, me vez de interferir durante a alimentação de outra espécie, pode ser mais eficiente somente esperar a sua vez. As duas espécies que tiveram interações mais fortes foram Colibri serrirostris e Leucochloris albicollis, que têm aproximadamente o mesmo tamanho (os dois pesam aproximadamente $6,2 \mathrm{~g}$; dados não 


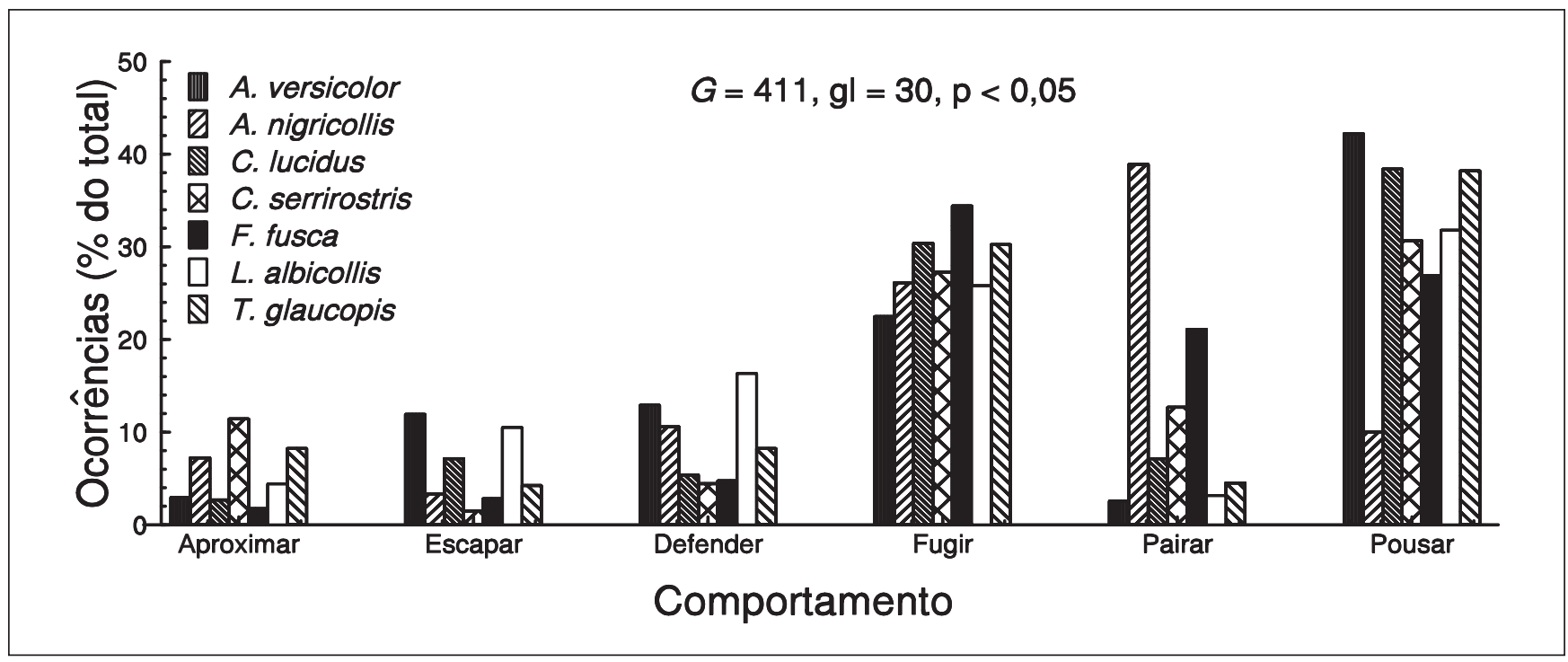

Figura 4 - Porcentagem de ocorrência dos diferentes comportamentos para cada espécie de beija-flor Fonte: Dados da pesquisa.

publicados pelos autores). A única espécie dentro da mesma faixa de peso (com diferença menor que $1 \mathrm{~g}$ ) é Clytolaema rubricauda $(6,7 \mathrm{~g}$, dados não publicados pelos autores), mas é rara no local. Também, uma vez que os bebedouros atraem várias espécies cujos comportamentos naturais podem sermuito diferentes (graças ao tamanho, tipo de flor preferido, entre outras coisas) ou que não se encontram frequentemente na natureza, podem não se ver mutuamente como competidoras nestes bebedouros.

A distribuição temporal deste conjunto de espécies também pode ser importante para a divisão dos recursos (31). Para comprovar esta possibilidade, as amostras devem estar padronizadas em relação ao tempo, o que não foi feito nesta pesquisa pela metodologia de vídeo-filmagem. Visto que podem ocorrer mais de 600 visitantes em uma amostra, não foi possível planejar para controlar pelo horário. Não ficou claro no início desta pesquisa como controlar por meio do horário; além disso, a temperatura anual varia muito e não sabemos quais fatores (hora do dia, foto-período, precipitação, entre outros) devem ser considerados também. Recomenda-se que estudos futuros procurem controlar as atividades em relação a horas do dia.

Apesar de não gerar hierarquias, é evidente que às vezes os indivíduos parecem estar evitando interagir. Por exemplo, é claro que durante alguns meses espécies que estavam na área como focais

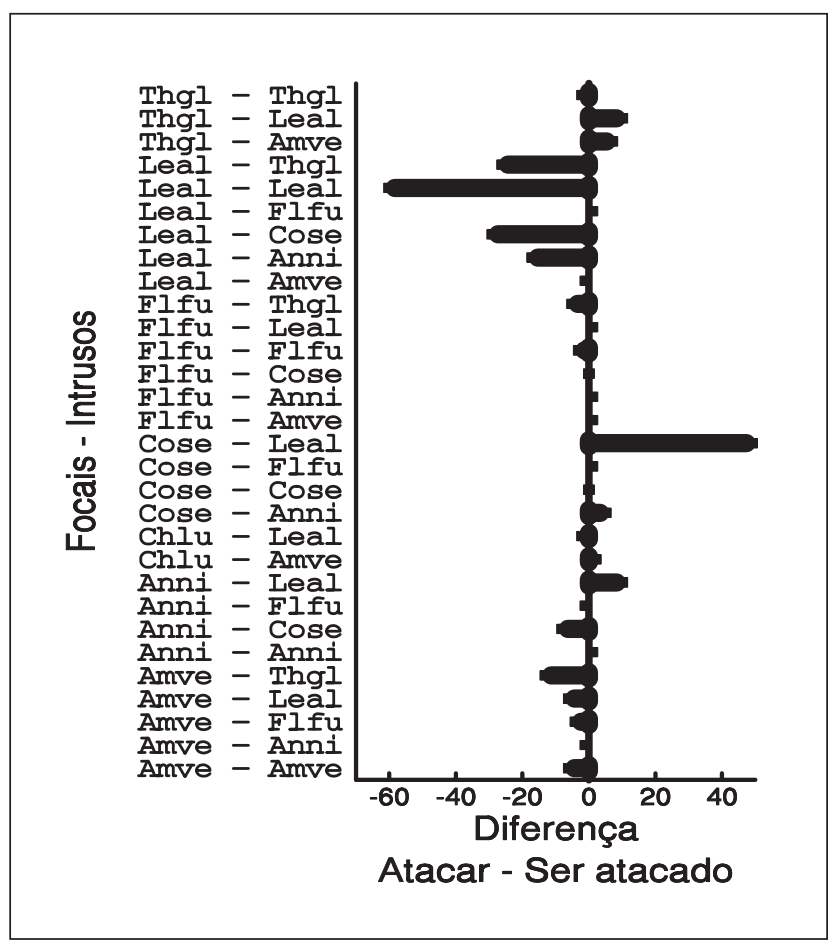

Figura 5 - Padrão de interações agonísticas inter e intraespecíficas. O comprimento das barras indica a intensidade da interação (atacar - ser atacado) representada para cada par de espécies. As barras em sentido negativo indicam que a espécie focal (coluna da esquerda) é mais atacada do que ataca a intrusa (coluna da direita)

Fonte: Dados da pesquisa. 


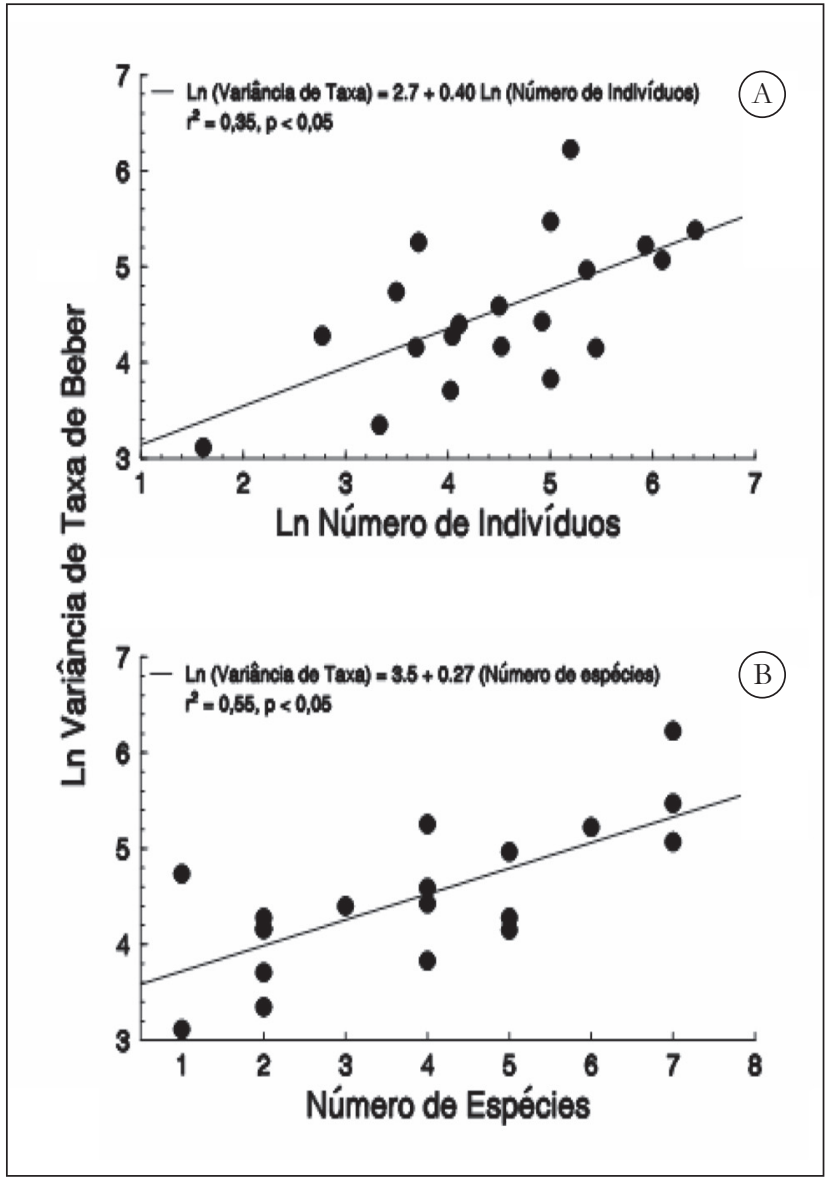

Figura 6 - A - Variação na taxa de uso do recurso artificial e número de indivíduos; B - Variação na taxa de consumo do recurso e número de espécies

Fonte: Dados da pesquisa.

não estavam interagindo neste período nas filmagens. No início de 2009, Amazilia versicolor não se comportou como intrusa e Chlorostilbon lucidus quase nunca se aproximou (Figura 2). Estas duas espécies são pequenas, e possivelmente evitam aproximar-se do bebedouro quando um indivíduo de outra espécie está pousado. Além disso, algumas espécies tendem a se aproximar enquanto outras tendem a escapar (Figura 4). Possivelmente estas interações gerem uma hierarquia, mas, considerando-se que existam muitas combinações de interações possíveis, o " $n$ " de algumas interações específicas foi pequeno. Recomendamos que, em estudos futuros, em vez de monitorar $90 \mathrm{~min}$ por dia, seja feito o monitoramento uma ou duas vezes por mês, sendo o acompanhamento realizado durante mais horas por dia. Assim, pode-se conseguir réplicas no mesmo dia, com mais interações e também controladas pela hora do dia. As interações mais claras foram entre espécies do mesmo tamanho, situação na qual se espera que haja mais interações (8). As espécies Leucochloris albicollis e Thalurania glaucopis mostraram uma interação em que T. glaucopisé dominante (Figura 5). Esta interação pode implicar interferência na natureza em que a dominância pode determinar o acesso a um recurso (32).

Dado que interações complexas foram observadas, ainda permaneceu obscuro o porquê da variabilidade anual no número de espécies e indivíduos. A riqueza de espécies na área de estudo é alta: ao total, observaram-se 12 espécies. No entanto, esta diversidade pode ser maior, pois Hylocharis chrysura, Lophornis chalybeus e Aphantochroa cirrochloris, cuja distribuição geográfica permite inferir a sua presença na região (26), não foram ainda observadas no local de estudo. A alta riqueza verificada na região ainda não é bem entendida, tanto no que diz respeito ao que a gera quanto do porquê deste ciclo anual. Em alguns estudos, ciclos anuais são entendidos como consequências de variabilidade em termos de recursos limitados, no caso, flores (33). Mas é difícil explicar como uma ou duas espécies sempre ocorrem na região $(L$. albicollis, T. glaucopis, Figura 2) enquanto outras não. É possível que a combinação de recursos ou adaptações as condições locais permitam que algumas espécies permaneçam na área. Por exemplo, L. albicollis é de distribuição predominantemente subtropical (26), e talvez apresente adaptações para suportar o inverno nesta região. Estudos futuros devem procurar mais informações sobre os recursos utilizados por estas espécies para saber quais são os fatores limitantes.

Esta comunidade de beija-flores tem dois picos de visitação aos bebedouros, na primavera e no outono (Figuras 1 e 2). A evidência sugere que são mais comuns durante as migrações e menos comuns na época de reprodução ou durante o inverno. Até agora, alguns ninhos antigos de L. albicollis foram encontrados no solo, caídos de araucárias. Mas ainda nenhum ninho de outras espécies foi encontrado nas proximidades. $\mathrm{O}$ motivo das espécies não se reproduzirem na área ainda não está claro.

\section{Conclusão}

Esta comunidade de beija-flores, composta por 12 ou mais espécies, mostra uma riqueza interessante para a região. Todavia, a comunidade não 
mostra uma forte hierarquia de interações entre as espécies. Esta falta de hierarquia pode ocorrer em virtude da grande variação de tamanho entre as espécies, suportado pela interação mais forte entre duas espécies do mesmo tamanho. A sazonalidade desta comunidade sugere dois picos, um durante a primavera e outro durante o outono. Descobrir o motivo das espécies aparentemente não se reproduzirem na área ajudaria a entender os ciclos anuais e identificar se existem outros recursos importantes além da energia fornecida pelos bebedouros.

\section{Referências}

1. Ricklefs RE. A economia da natureza. 5a ed. Rio de Janeiro: Guanabara Koogan; 2003.

2. Sick H. Ornitologia brasileira. Rio de Janeiro: Nova Fronteira; 1997.

3. Cody ML. Interspecific territoriality among hummingbirds species. Condor. 1968;70:270-1.

4. Stiles FG, Wolf LL. Hummingbird territoriality at a tropical flowering tree. Auk. 1970;87(3):467-91.

5. Brown JA, Browers MA. Community organization in hummingbirds: Relationships between morphology an ecology. Auk. 1985;102:251-69.

6. Snow DW, Snow BK. Feeding ecology of hummingbirds in the Serra do Mar, southeastern Brazil. Hornero. 1986;12:286-96.

7. Cotton PA. Temporal partitioning of a floral resource by territorial hummingbirds. Ibis. 1998;140:647-53.

8. Antunes AZ. Partiha de néctar de Eucalyptus spp., territorialidade e hierarquia de dominância em beija-flores (Aves: Trochilidae) no sudeste do Brasil. Ararajuba. 2003;11:39-44.

9. Brown JL. The evolution of diversity in avian territorial systems. Wilson Bulletin. 1964;76:160-9.

10. Gill FB. Proximate costs of competition for nectar. American Zoologist. 1978;18:753-63.

11. Gass CL. Rufous hummingbird feeding territoriality in a suboptimal habitat. Canadian Journal of Zoology. 1978;56:1535-9.

12. Copenhaver C, Ewald PW. Cost of territory establishment in hummingbirds. Oecologia. 1980;46:155-60.
13. Carpenter FL, MacMillen RE. Threshold model of feeding territoriality and test with a Hawaiian honeycreeper. Science. 1976;194(4265):639-42.

14. Stiles FG. Ecological and evolutionary implications of bird pollination. American Zoologist. 1978;18(4):715-27.

15. Dearborn DC. Interspecific territoriality by a rufous-tailed hummingbird (Amazilia tracat): effects of intruder size and resource value. Biotropica. 1998;30:306-13.

16. Krebs JR, Davies NB. Introdução à ecologia comportamental. São Paulo: Atheneu; 1996.

17. Gass CL. Territory regulation, tenure, and migration in rufous hummingbirds. Canadian Journal of Zoology. 1979;56:914-23.

18. Wolf LL. Aggressive social organization in nectarivorous birds. American Zoologist. 1978;18:765-778.

19. Kodric-Brown A,BrownJH. Influence of economics, interspecific competition, and sexual dimorphism on territoriality of migrant rufous hummingbirds. Ecology. 1978;59:285-96.

20. Ewald PW, Orians GH. Effects of resource depression on use of inexpensive and escalated aggressive behaviour: experimental tests using Anna hummingbirds. Behavioral Ecology and Sociobiology. 1983;12:95-101.

21. Ewald PW, Rohwer S. Age, colouration and dominance in nonbreeding hummingbirds: a test of the asymmetry hypothesis. Behavioral Ecology and Sociobiology. 1980;7:273-9.

22. Hueck K. Florestas da América do Sul: ecologia, composição e importância econômica. Brasília: Universidade de Brasília; 1972.

23. Maack R. Geografia física do Estado do Paraná. Rio de Janeiro: José Olympio; 1968.

24. Roderjan CV, Galvão F, Kuniyoshi YS, Hatschbach GG. As unidades fitogeográficas do Estado do Paraná. Ciência \& Ambiente. 2002;24:75-92.

25. Instituto Agronômico do Paraná IAPAR. Cartas climáticas do estado do Paraná. [acesso 12 mar. 2009]. Disponível em: http://www.iapar.br/modules/ conteudo $/$ conteudo.php?conteudo $=856$

26. Sigrist T. Guia de campo: aves do Brasil oriental. Valinos: Avis Brasilis; 2007. 
27. Narosky T, Yzurieta D. Aves de Argentina y Uruguai: guia para la identificacion. Buenos Aires: Vazquez Mazzini; 2003.

28. Howell SNG, Gardali T. Phenology, sex ratios, and population trends of Selasphorus hummingbirds in central coastal California. Journal of Field Ornithology. 2003;74(1):17-25.

29. Wethington SM, Russell SM. The Seasonal distribution and abundance of hummingbirds in oak woodland and riparian communities in southeastern Arizona. The Condor. 2003;105(3):484.

30. Abreu CRM, Vieira MF. Os beija-flores e seus recursos florais em um fragmento florestal de Viçosa, Sudeste brasileiro. Lundiniana. 2003;2:129-34.

31. Kronfeld-Schor N, Dayan T. Partitioning of time as an ecological resource. Annual Review of Ecology, Evolution, and Systematics. 2003;34(1):153-81.
32. Camfield AF. Resource value affects territorial defense by Broad-tailed and Rufous hummingbirds. Journal of Field Ornithology. 2006;77(2):120-5.

33. Cotton PA. Seasonal resource tracking by Amazonian hummingbirds. Ibis. 2007;149(1):135-42.

Recebido: 14/10/2008

Received: 10/14/2008

Aprovado: 14/10/2009

Approved: 10/14/2009 